\title{
Planejamento urbano participativo por meio da utilização de novas tecnologias: uma avaliação por especialistas
}

\author{
Participatory urban planning through the use of new technologies: \\ an evaluation by experts
}

Geisa Bugg ${ }^{[0]}$, Antônio Tarcísio da Luz Reis ${ }^{[b]}$

[a] Universidade Feevale, Novo Hamburgo, RS, Brasil.

[b] Universidade Federal do Rio Grande do Sul - UFRGS, Faculdade de Arquitetura, Programa de Pós-graduação em Planejamento Urbano - PROPUR, Porto Alegre, RS, Brasil.

\section{Resumo}

O objetivo deste artigo é avaliar a aceitação, por parte dos especialistas, da participação pública e da utilização de novas tecnologias, bem como investigar como eles avaliam metodologias alternativas, como a Participação Pública com Sistema de Informação Geográfica (PPSIG). Assume-se que novas abordagens metodológicas, que façam uso das Tecnologias da Informação e Comunicação (TIC) e dos Sistemas de Informação Geográfica (SIG), podem aperfeiçoar os processos de participação pública no planejamento urbano, tendo em vista a dificuldade de se incorporar a perspectiva da população e a necessidade de renovação das práticas para se lidar com os fluxos de informação da era digital. Os procedimentos metodológicos incluem a aplicação de questionários e a realização de entrevistas com arquitetos e urbanistas que atuam na área de planejamento urbano. Os resultad os apontam que, apesar das barreiras institucionais e da necessidade de maior capacitação técnica, há aceitação quanto à participação pública e à utilização de novas ferramentas, e que a PPSIG pode auxiliar na difícil tarefa de incorporar a perspectiva do usuário do espaço urbano, na opinião dos respondentes.

Palavras-chave: Planejamento participativo. PPSIG. TIC.

\section{Abstract}

This paper aims to evaluate the experts acceptance of the public participation, the use of new technologies, and to investigate how they evaluate alternative methodologies such as the Public Participation Geographic Information Systems (PPGIS). We assume that new methodological approaches, using Information and Communication Technology (ICT) and Geographic Information Systems (GIS), can improve public participation in urban planning processes, given the difficulty to include the population perspective, and the need to renew the practices for dealing with the flow of information in the digital era. Questionnaires and interviews were conducted with architects working in the urban planning area, as part of the methodological procedures. The results show

GB é Arquiteta e Urbanista; Doutora pelo PROPUR/UFRGS, e-mail: geisa@feevale.br

ATLR é Arquiteto e Urbanista; Doutor pela Pos Graduate Research School, Oxford Brookes University, e-mail: tarcisio.reis@ufrgs.br 
that despite institutional barriers and the necessity of technical training, the public participation and the use of new tools are accepted, and that PPSIG can help in the difficult task of incorporating the urban space users perspective, in the respondents opinion.

Keywords: Participatory planning. PPGIS. ICT.

\section{Introdução}

O planejamento urbano normalmente tem sido baseado na coleta e na troca de informações entre diferentes partes interessadas. Contudo, uma mudança no modelo informacional, em consequência da revolução das tecnologias digitais, tem gerado um impacto significativo em como se desenvolve todo o processo (Haller \& Höffken, 2010). Para acompanhar as mudanças tecnológicas, faz-se necessário adicionar novas ferramentas que permitam exibir e gerenciar novos fluxos de informações (Pereira et al., 2013). Logo, tal mudança também vai exigir alterações no modus operandi do planejamento urbano, ainda muito influenciado pelo pensamento do modelo racional (Yigitcanlar, 2006; Horelli et al., 2013), segundo o qual, os especialistas seriam capazes de considerar as melhores soluções para os cidadãos e para a sociedade como um todo, sem incluir, portanto, nenhuma forma de participação da sociedade civil nas discussões de propostas para a cidade (Villaça, 2005).

$\mathrm{Na}$ era da informação e da sociedade em rede, ferramentas digitais estão se tornando onipresentes na vida cotidiana e possuem alto potencial para a coleta de dados socioespaciais e temporais, o que é completamente diferente dos modelos estáticos de coleta de dados que o planejamento urbano comumente utiliza (Friedmann, 2007; Batty et al., 2012). A ubiquidade das Tecnologias da Informação e Comunicação (TIC) está produzindo ambientes urbanos que são completamente diferentes de tudo o que se experimentou até agora, nos quais um grupo muito maior de cidadãos pode aderir (Pfeffer et al., 2013).

Antigamente, os profissionais eram os únicos produtores e usuários das informações relativas às questões urbanas. Entretanto, hoje, qualquer pessoa pode facilmente produzir um mapa e publicá-lo on-line. Assim, mesmo que involuntariamente, está ocorrendo um aumento da consciência da informação geográfica pelo público, o que pode ser considerado uma revolução nesse campo, pois possibilita que ferramentas do Sistema de Informação Geográfica (SIG) possam ser compreendidas de maneira rápida e eficaz, sem haver a necessidade de imersão em atividades profissionais (Hudson-Smith \& Crooks, 2008).

Por conseguinte, o mundo digital está transformando a possibilidade de participação pública no planejamento urbano (Batty et al., 2012). A capacidade de todos os cidadãos se comunicarem uns com os outros, até mesmo com seus representantes, além das novas formas de se relacionar com o espaço urbano, abre novas frentes para a ideia de que os cidadãos possam desempenhar um papel ativo no planejamento urbano. Mas, apesar disso, e dos mais de 40 anos de história do planejamento participativo (considerando, por exemplo, os processos de planejamento e construção de habitações na Europa nos anos de 1960 e 1970), a participação pública ainda não conseguiu entrar no mainstream do planejamento urbano de forma consistente (Horelli, 2002).

Em parte, tal acontecimento ocorre porque envolver o público não é uma tarefa simples e direta. Participação plena implica em responsabilização e poderes partilhados. Para se alcançar esse nível, existe uma série de barreiras que vão desde a relevância dada às opiniões e posições do público, passando pela credibilidade e idoneidade destas (Corburn, 2003), até os entraves institucionais (Brown, 2012). Nas palavras de Forester (2006, p. 447): "Fácil de pregar, mas difícil de praticar, participação pública eficaz no planejamento e na gestão pública exige sensibilidade e técnica, imaginação e coragem".

De tal modo, ainda não se conseguiu abordar a perspectiva da população de forma consistente (Kahila \& Kyttä, 2009). A literatura destaca, por exemplo, que há grande dificuldade em se passar de um sistema de planejamento dominado por especialistas para um que daria voz a diferentes interessados (Wallin \& Horelli, 2012) e que o planejamento urbano, em geral, utiliza somente dados oficiais, nos quais as pessoas são levadas em consideração apenas na forma de estatísticas agregadas (Friedmann, 2007).

Distintos autores defendem a necessidade de uma reformulação no planejamento urbano por meio da 
utilização de tecnologias que permitam a criação de técnicas e metodologias mais interativas, emancipatórias e colaborativas (Yigitcanlar, 2006; Horelli et al., 2013). Nesse sentido, os recentes avanços tecnológicos em torno das TIC (em especial, a internet) e dos SIG envolvem novas perspectivas.

Se a internet é o principal meio de troca de informações e comunicação da atualidade, os SIG são uma tecnologia que desempenha um papel importante na coleta, tratamento e disseminação de informações espaciais - e a maioria das informações necessárias à formulação de políticas urbanas contém um componente espacial (Sieber, 2006). Para Yigitcanlar (2006), o uso efetivo das TIC e dos SIG no planejamento urbano representa a possibilidade de se estabelecer um sistema permanente de coleta das percepções do público sobre o espaço urbano, o que é apontado como essencial para que ele se torne mais colaborativo.

Nessa direção, estudos recentes apontam que a Participação Pública com Sistema de Informação Geográfica (PPSIG) possui potencial para aprimorar a participação do público no planejamento urbano (Kahila \& Kyttä, 2009; Poplin, 2012). A PPSIG utiliza ferramentas dos SIG para a participação pública, conectando a capacidade técnica deles ao conhecimento local (Sieber, 2006). 0 público participa produzindo mapas e/ou dados espaciais que representam a sua percepção do espaço urbano em questão (Bugs, 2014).

A PPSIG surgiu nos anos de 1990 a partir de reflexões sobre a interface do SIG com a sociedade. No início dos anos de 2000, chegou a ser considerada uma evolução dos métodos clássicos de participação (Carver, 2001). Mas o entusiasmo inicial começou a diminuir por volta de 2005 (Poplin, 2012), quando vários problemas foram levantados, tais como o reconhecimento de que termos e conceitos como "participação" e "empoderamento" foram utilizados de forma acrítica (Hall et al., 2010). Então, quase que concomitantemente, os mashups de mapas e o mapeamento voluntário emergiram na web 2.0. Logo, surgiram experiências tirando proveito dos mapas on-line interativos e do aumento do conhecimento da informação geográfica pelo público. Esses projetos atraíram os cidadãos para o uso de ferramentas de participação baseadas em mapas on-line (Poplin, 2012), e o interesse na PPSIG se renovou. Porém o tema ainda é, relativamente, pouco explorado a partir da perspectiva dos profissionais que trabalham com planejamento urbano, principalmente no contexto brasileiro. A maioria das experiências existentes foi desenvolvida por geógrafos, com foco na produção de cartografia, ou por profissionais da tecnologia da informação, com foco no desenvolvimento tecnológico.

Em suma, estão em curso mudanças na sociedade contemporânea fomentadas pelas revoluções digital e geoespacial, sem que exista um maior conhecimento acerca do efeito de tais mudanças sobre o planejamento urbano, o que tem sido tema de debate entre os profissionais, conforme apontam Pereira et al. (2013). Logo, faz-se necessário entender como se dá o planejamento urbano participativo utilizando novas tecnologias, na opinião dos especialistas. Assim sendo, esta pesquisa tem como objetivo avaliar a aceitação, por parte dos planejadores, da participação do público no planejamento urbano e da utilização de novas tecnologias, assim como investigar como esses profissionais avaliam metodologias participativas alternativas, tal como a PPSIG.

\section{Metodologia}

Os dados foram coletados por meio de um questionário aplicado a arquitetos e urbanistas (AU) que trabalham com planejamento urbano no Rio Grande do Sul, especificamente em prefeituras, universidades e empresas privadas, e que desenvolvem tanto planos quanto projetos urbanos. Ainda que o planejamento urbano seja realizado por profissionais de diversas áreas, optou-se por trabalhar apenas com AU pela maior viabilidade de acesso a esses profissionais. Ainda, via de regra, o AU é o profissional mais identificado com a atividade de planejamento urbano, pois é o único habilitado para assinar a responsabilidade técnica de um plano diretor no Brasil.

No total, foram distribuídos 100 questionários via e-mail, obtendo uma taxa de retorno de $42 \%$ ( 42 de 100). O questionário continha 19 perguntas, das quais as três primeiras diziam respeito às características dos respondentes e outras duas questões abordavam o uso dos SIG. As demais perguntas ou afirmações retiradas da revisão da literatura tratavam da participação do público no planejamento urbano, das novas tecnologias e da PPSIG. A maior parte dos respondentes era do sexo feminino $(64,3 \%$, ou 27 de 42), possuía entre 26 e 40 anos $(59,5 \%$, ou 25 de 42) e tinha pós-graduação $(69,1 \%$, ou 29 de 42). 
Adicionalmente, a maioria respondeu ter algum tipo de capacitação em SIG (78,6\%, ou 33 de 42) e utilizá-lo em suas atividades profissionais ( $62 \%$, ou 26 de 42$)$.

Ademais, a fim de interagir com os participantes e aprofundar a investigação, foram realizadas entrevistas com sete $\mathrm{AU}$ : dois servidores públicos, dois profissionais liberais, dois docentes e um estudante de pós-graduação.

\section{Resultados}

Aceitação da participação do público e da utilização de novas tecnologias

A expressiva maioria dos $\mathrm{AU}(88,1 \%$, ou 37 de 42$)$ concorda totalmente $(40,5 \%$, ou 17 de 42$)$ ou concorda (47,6\%, ou 20 de 42) com a afirmação de que "Os habitantes são peças fundamentais no planejamento urbano, pois conhecem a realidade e os problemas locais melhor do que ninguém" (Tabela 1). Logo, pode-se afirmar que, segundo os respondentes, os habitantes devem fazer parte do planejamento urbano, pois o seu conhecimento sobre a cidade é fundamental. Contudo, nos comentários, parte dos AU discordou da expressão "melhor do que ninguém". Por exemplo: "Conhecem de forma cotidiana e extensa, mas não 'melhor do que ninguém!' Esse exagero coloca todo e qualquer saber diverso do local em xeque, o que não é apropriado" (AU 52).

Destaca-se também a recorrência de "poréns" nos comentários, o que, por vezes, transmite certa conotação de hierarquia: "Eu diria que eles conhecem muito bem uma faceta dos problemas, mas, sem um embasamento técnico, eles podem ter uma visão distorcida e parcial dos problemas" (AU 29).

Sem embargo, prevalece a visão de que a opinião do público deve considerar uma camada de informação tão importante e necessária quanto todas as outras. Conforme comentários: "São peças importantes não porque sabem mais do que ninguém, mas porque são decisores tão importantes quanto qualquer outro" (AU 35). 0 entrevistado D sintetiza a questão da seguinte forma:

Teríamos que discutir esta questão da validade da opinião das pessoas, porque muitas pessoas não acreditam que seja válido o olhar do cidadão [...] e o olhar do cidadão é verdadeiro porque é o olhar do cidadão.

Quanto à afirmação "Em muitos aspectos o modus operandi do planejamento urbano não responde às demandas dos cidadãos e aos desafios da complexidade urbana", a expressiva maioria dos respondentes $(93,1 \%$, ou 39 de 42) concorda totalmente (45,2\%, ou 19 de 42$)$ ou concorda (47,6\%, ou 20 de 42) (Tabela 1). Alguns respondentes consideram que isso ocorre "justamente por faltar a visão do cidadão sobre o tema" (AU 41). Para muitos, entretanto, isso ocorre porque a vontade política, em geral, prevalece sobre as indicações técnicas:

É preciso discernir o modo como se opera o planejamento urbano de fato do modo como deveria ser ou se espera que seja. Pois as propostas e diretrizes, enfim, todo o produto do trabalho dos planejadores é descartado para atender a desejos políticos (AU 29).

Tabela 1 - Os habitantes são peças fundamentais e o modus operandi não responde às demandas

\begin{tabular}{ccccc}
\hline & $\begin{array}{c}\text { Os habitantes sũo peças fundamentais no planejamento } \\
\text { urbano, pois conhecem a realidade e os problemas } \\
\text { locais melhor do que ninguém. }\end{array}$ & $\begin{array}{c}\text { Em muitos aspectos, o modus operandi do } \\
\text { planejamento urbano não responde às demandas dos } \\
\text { cidadáos e cos desafios da complexidade urbana. }\end{array}$ \\
\cline { 2 - 5 } & $\mathbf{N}^{\circ}$ de AU & 40,5 & 19 & $\%$ \\
\hline CT & 17 & 47,6 & 20 & 45,2 \\
C & 20 & 11,9 & 2 & 47,6 \\
NCND & 5 & 0 & 1 & 4,8 \\
D & 0 & 0 & 0 & 2,4 \\
DT & 0 & 100 & 42 & 0 \\
Total & 42 & & & 100 \\
\hline
\end{tabular}

Fonte: Elaborado pelos autores.

Nota: $\mathrm{AU}=$ arquitetos e urbanistas; $\mathrm{CT}=$ concordo totalmente; $\mathrm{C}=$ concordo; $\mathrm{NCND}=$ nem concordo nem discordo; $\mathrm{D}=$ discordo; $\mathrm{DT}=$ discordo totalmente. 
Logo, as barreiras institucionais e políticas ainda são grandes entraves para a prática do planejamento urbano participativo, conforme aponta Brown (2012).

Com relação à afirmação de que "Os planejadores tendem a desconsiderar os dados produzidos pelos cidadãos em suas atividades cotidianas", embora a maioria dos $\mathrm{AU}(57,1 \%$, ou 24 de 42$)$ concorde totalmente $(21,4 \%$, ou 9 de 42$)$ ou concorde $(35,7 \%$, ou 15 de 42), o número daqueles que nem concordam nem discordam também é relevante $(38,1 \%$, ou 16 de 42) (Tabela 2).

Nos comentários, os AU ressaltaram a dificuldade de acesso a esses dados. Outros defenderam: "Mesmo que desconexos de instrumentos e da lógica dos SIG, planejadores estão se utilizando de informações disponíveis pelos usuários na internet, como fotos, vídeos etc." (AU 26). Mas também houve uma crítica mais direta:

Diferente de muitas áreas que já se utilizam dos dados gerados pelos cidadãos de forma voluntária ou não, o planejamento está longe disso [...] não temos o costume e a técnica para buscar estes dados e torná-lo parte do processo (AU 41).

Observa-se, portanto, que não há consenso entre os AU respondentes, confirmando que ainda não se tem um entendimento de como o planejamento urbano acompanha as mudanças tecnológicas, conforme apontam Pereira et al. (2013), e evidenciando a necessidade de renovação das práticas de coleta e de interpretação de dados, corroborando a literatura (Pfeffer et al., 2013; Horelli et al., 2013).
Quanto à afirmação de que "Os cidadãos, a partir das transformações socioculturais e tecnológicas, estão capacitados a atuar e influenciar o modo de pensar e agir sobre as cidades", a maioria dos $\mathrm{AU}(73,8 \%$, ou 31 de 42$)$ concorda totalmente (19\%, ou 8 de 42$)$ ou concorda ( $54,8 \%$, ou 23 de 42$)$ (Tabela 2). No entanto, por um lado, alguns fizeram ressalvas:

Não penso que sejam as 'transformações socioculturais e tecnológicas' que tenham mudado as coisas [...] as tecnologias são mero instrumento. Participei de momentos muito intensos de planejamento urbano participativo na década de 80 (AU 24); e

Uma pessoa ter acesso a smartphones, tablets etc., não significa que esteja apto [...]. Porém, utilizando-se de uma interface de fácil entendimento e manuseio, facilitaria. Ainda, acho que a inovação tecnológica é uma ferramenta muito interessante [...], mas acredito que abrange apenas uma parcela da população (AU 37).

Por outro lado, outros questionados concordam que a ubiquidade das TIC está produzindo transformações significativas:

As novas ferramentas e, principalmente, sua acessibilidade crescente permitem que a interação dos cidadãos com o planejamento seja mais direta. Informa-se mais e assim tem mais capacidade de opinar ou tomar decisão (AU 41); $\mathrm{e}$

Tabela 2 - Os planejadores tendem a desconsiderar os dados produzidos pelos cidadãos, e estes, a partir das transformações socioculturais e tecnológicas, estão capacitados

\begin{tabular}{|c|c|c|c|c|}
\hline & \multicolumn{2}{|c|}{$\begin{array}{l}\text { Os planejadores tendem a desconsiderar os dados } \\
\text { produzidos pelos cidadãos em suas atividades } \\
\text { cotidianas. }\end{array}$} & \multicolumn{2}{|c|}{$\begin{array}{l}\text { Os cidadãos, a partir das transformações socioculturais } \\
\text { e tecnológicas, estão capacitados a atuar e influenciar } \\
\text { o modo de pensar e agir sobre as cidades. }\end{array}$} \\
\hline & $\mathrm{N}^{0}$ de $\mathrm{AU}$ & $\%$ & $N^{\circ}$ de AU & $\%$ \\
\hline CT & 9 & 21,4 & 8 & 19 \\
\hline C & 15 & 35,7 & 23 & 54,8 \\
\hline NCND & 16 & 38,1 & 10 & 23,8 \\
\hline$D$ & 2 & 4,8 & 1 & 2,4 \\
\hline DT & 0 & 0 & 0 & 0 \\
\hline Total & 42 & 100 & 42 & 100 \\
\hline
\end{tabular}

Nota: Elaborado pelos autores.

Legenda: $\mathrm{AU}=$ arquitetos e urbanistas; $\mathrm{CT}=$ concordo totalmente; $\mathrm{C}=$ concordo; $\mathrm{NCND}=$ nem concordo nem discordo; $\mathrm{D}=$ discordo; $\mathrm{DT}=$ discordo totalmente. 
Eu acredito nesta ideia de que, do ponto de vista contemporâneo, as pessoas podem ser consideradas sensores e nós teríamos essa ferramenta de mapeamento capaz de capturar isso de um modo mais rápido (Entrevistado D).

Pode-se discutir mais a fundo se os avanços tecnológicos estão empoderando ou não os cidadãos, mas, indiscutivelmente, estão produzindo mudanças nas relações do cidadão com o espaço urbano e com o governo. Assim, reforça-se o entendimento de que os avanços tecnológicos demandam mudanças na prática do planejamento urbano. $\mathrm{O}$ entrevistado I resume a questão:

Essa coisa de o usuário poder decidir coisas pela tecnologia vai até um certo ponto, mas ele não consegue decidir coisas mais estratégicas, então o planejamento não vai deixar de existir, mas ele tem que mudar, se reformular, ser mais rápido nas respostas.

No mesmo viés, a expressiva maioria dos AU (92,9\%, ou 39 de 42$)$ concorda totalmente $(52,4 \%$, ou 22 de 42) ou concorda (40,5\%, ou 17 de 42) que "Atualmente se faz obrigatório adicionar novas ferramentas no planejamento urbano, as quais podem exibir e gerenciar novos fluxos de informações" (Tabela 3). Os comentários confirmam que os AU desejam utilizar novas tecnologias: "Não se pode planejar como se fazia anos atrás. Ter acesso aos dados disponíveis ou às fontes é fundamental para repostas mais consistentes" (AU 41).
Quanto à afirmação de que "Ainda não se dispõe da capacitação técnica necessária para utilização das TIC e dos SIG no planejamento urbano", embora a maioria dos respondentes $(54,7 \%$, ou 23 de 42$)$ concorde totalmente $(9,5 \%$, ou 4 de 42$)$ ou concorde $(45,2 \%$, ou 19 de 42$)$, a porcentagem daqueles que nem concorda nem discorda não é desprezível (23,8\%, ou 10 de 42 ) (Tabela 3). Nos comentários, evidencia-se que, alguns dos que nem concordam nem discordam, o fazem por não terem conhecimento a respeito: "Não tenho conhecimento que me permita responder isso. Talvez os técnicos tenham a capacitação, mas não tenham infraestrutura e suporte tecnológico adequado nasinstituições de atuação" (AU 12).

Recentemente, o Censo dos Arquitetos e Urbanistas do Brasil, realizado pelo Conselho de Arquitetura e Urbanismo (CAU, 2014), revelou que $28,04 \%$ dos profissionais possuem conhecimento bom de softwares de geoprocessamento, 33,81\%, ruim, e $38,15 \%$ desconhecem. Esse fato reforça o entendimento de que parte considerável dos AU ainda não dispõe de capacitação técnica adequada para utilização dos SIG. Aqueles respondentes que concordam com essa visão comentaram: "Realmente, na minha opinião, falta capacitação técnica, inclusive dentro das prefeituras. Poucos técnicos se interessam e se capacitam nesta área" (AU 37); " "Está começando, mas não quer dizer que todas as pessoas que trabalhem com planejamento urbano vejam esse potencial" (Entrevistado J). Logo, a necessidade da capacitação técnica em SIG existe.

Nas entrevistas, foi perguntado se o AU está preparado para lidar com a opinião da população e qual a disposição

Tabela 3 - Faz-se obrigatório adicionar novas ferramentas e não se dispõe da capacitação técnica necessária

\begin{tabular}{|c|c|c|c|c|}
\hline & \multicolumn{2}{|c|}{$\begin{array}{l}\text { Atualmente, faz-se obrigatório adicionar novas } \\
\text { ferramentas no planejamento urbano, as quais podem } \\
\text { exibir e gerenciar novos fluxos de informaçōes. }\end{array}$} & \multicolumn{2}{|c|}{$\begin{array}{l}\text { Ainda não se dispõe da capacitação técnica necessúria } \\
\text { para utilização das TIC e dos SIG no planejamento } \\
\text { urbano. }\end{array}$} \\
\hline & $N^{0}$ de AU & $\%$ & $\mathbf{N}^{\circ}$ de $\mathrm{AU}$ & $\%$ \\
\hline CT & 22 & 52,4 & 4 & 9,5 \\
\hline$c$ & 17 & 40,5 & 19 & 45,2 \\
\hline NCND & 3 & 7,1 & 10 & 23,8 \\
\hline$D$ & 0 & 0 & 8 & 19,1 \\
\hline DT & 0 & 0 & 1 & 2,4 \\
\hline Total & 42 & 100 & 42 & 100 \\
\hline
\end{tabular}

Fonte: Elaborado pelos autores.

Nota: $\mathrm{AU}$ = arquitetos e urbanistas; $\mathrm{TIC}=$ Tecnologias da Informação e Comunicação; $\mathrm{SIG}=$ Sistemas de Informaç̃ão Geográfica; $\mathrm{CT}$ = concordo totalmente; $\mathrm{C}=$ concordo; $\mathrm{NCND}=$ nem concordo nem discordo; D = discordo; DT = discordo totalmente. 
e a capacidade de usarem essa camada de informação. Percebe-se que alguns AU ainda veem o público como tendo um déficit de conhecimento, conforme discutido por Corburn (2003). Por exemplo: "A população não consegue perceber toda a dimensão do urbano que é extremamente complexa. Nós, com conhecimento, temos dificuldades, imagina a população" (Entrevistado M). De outra parte, na opinião do entrevistado 0: “Tem a dimensão política [...], tem também o ranço de o arquiteto ser a única voz do processo, determinadas escolas formam muito nessa coisa autoral e transportam isso num discurso de cidade".

Portanto, há divergências nas opiniões. Mas deve-se ter em mente que se trata de um processo de mudança. Antigamente era feito de um jeito e atualmente está se mostrando a necessidade de uma outra maneira. A princípio, com o passar do tempo, a tendência é que essa questão seja suplantada, tendo em vista a crescente importância atribuída ao conhecimento local, que pressiona os profisisonais a mudar sua postura. Corroborando, o entrevistado $\mathrm{O}$ acredita que o $\mathrm{AU}$ tem de adotar uma postura diferente - de ouvinte - e trabalhar mais em prol dos processos participativos. Isso porque, segundo ele, o planejamento participativo, tal qual praticado atualmente, não fomenta o debate de opiniões.

Por fim, quanto ao papel do planejador urbano nos processos participativos, os entrevistados têm um entendimento semelhante àquele encontrado na literatura acerca da mediação dos diferentes interesses envolvidos no planejamento urbano, mas sem abdicar do seu conhecimento (Souza \& Rodrigues, 2004; Staffans et al., 2010; Mäntysalo et al., 2011). De acordo com o entrevistado D:

Eu vejo o serviço dos planejadores como um direito das pessoas [...] eu como morador da cidade quero dizer as coisas que eu penso, quero que alguém me preste um serviço [...] uma equipe de profissionais que faça a análise dos resultados, que julgue.

Os entrevistados também salientaram a necessidade de, nesse processo de mediação dos diferentes interesses, buscar-se a "consertação", ou seja, um pacto ou acordo entre as partes. Essa visão corrobora o pensamento do planejamento agonístico (Mäntysalo et al., 2011), o qual argumenta que o consenso, embora uma condição legítima, não deve ser mandatório, pois as diferentes racionalidades podem e devem coexistir. Assim, deve-se aprender a gerenciar o conflito intrínseco das diferentes racionalidades envolvidas no processo de planejamento urbano e buscar a pactuação. Segundo o entrevistado 0 , sendo a cidade uma manifestação física, se ela for produzida por meio de conflitos, vai expressar isto. Porém, a cidade também é um local de encontro, e, se não houver um projeto comum, abolir-se-á a cidade. $\mathrm{Na}$ sua visão, deve-se, no momento propositivo, interpretar esses conflitos e achar um ponto comum.

\section{Avaliação do método PPSIG}

Nas questões que abordaram especificamente o método PPSIG, foram considerados apenas os $19 \mathrm{AU}$ (45,2\%, ou 19 de 42$)$ que afirmaram ter conhecimento prévio do método. A totalidade desses respondentes concorda totalmente $(52,6 \%$, ou 10 de 19$)$ ou concorda (47,4\%, ou 9 de 19) com a afirmação de que "A PPSIG possibilita a inclusão do conhecimento local de forma sistemática em um banco de dados espacial que pode alimentar um sistema de suporte à decisão".

Nos comentários, um respondente destacou a necessidade de dados coletados serem transformados em informação útil, ou seja, que o dado seja analisado de forma consistente para ser utilizado no planejamento urbano. Em suas palavras:

O conhecimento local é fundamental, mas, se ele não estiver adequadamente estruturado (se o dado não for convertido em informação útil), ele pode acabar não contribuindo para um sistema de suporte à decisão eficiente (AU 55).

Similarmente, outros respondentes chamaram a atenção para a necessidade de conhecimento técnico adequado para analisar os dados coletados de forma consistente: "Isso depende muito do modo como esse tal dado qualitativo é inserido, ou pode-se incorrer facilmente em falsas correlações" (AU 29).

Quanto à afirmação de que "Com o método PPSIG, fatores de qualidade individualmente significativos (por exemplo, níveis de satisfação com os espaços urbanos) podem ser facilmente analisados em relação a outras camadas de informação (por exemplo, dados censitários)", a expressiva maioria dos respondentes $(89,4 \%$, ou 17 de 19$)$ concorda totalmente $(36,8 \%$, ou 7 de 19$)$ ou concorda (52,6\%, ou 10 de 19) (Tabela 4). 0 resultado confirma que a PPSIG possibilita a integração de informações qualitativas e quantitativas, de acordo com Kahila \& Kyttä (2009). Nesse sentido, um respondente afirmou que o cruzamento de informações só tem a agregar valor ao resultado final, já que haverá um cruzamento 
de dados que pode ajudar a se obter interpretações ou proposições projetais mais assertivas (AU 54).

A expressiva maioria dos respondentes $(84,2 \%$, ou 16 de 19) também concorda totalmente $(36,8 \%$, ou 7 de 19) ou concorda $(47,4 \%$, ou 9 de 19) com a afirmação de que "As informações coletadas com a PPSIG podem levar a soluções diferentes das que teriam sido alcançadas utilizando-se apenas fontes oficias de dados e o conhecimento especialista" (Tabela 4).

Nos comentários, entretanto, alguns AU expressaram ressalvas: "Não afirmaria que existiria uma dualidade entre a informação popular e a especializada" (AU 26); e "Sim, mas creio que seja importante saber qual o público que está realmente participando" (AU 46). De qualquer forma, a literatura (Kahila \& Kyttä, 2009; Staffans et al., 2010) já indica que os planejadores, inevitavelmente, precisarão desenvolver um entendimento mais profundo do conhecimento escondido nas experiências cotidianas dos indivíduos, bem como habilidades para lidar com ele. Isso implica na necessidade de reconsiderar suas formas de trabalho e os métodos por meio dos quais as informações de

Tabela 4 - Fatores de qualidade individualmente significativos podem ser facilmente analisados, e as informações coletadas com a PPSIG podem levar a solucõoses diferentes

\begin{tabular}{|c|c|c|c|c|}
\hline & \multicolumn{2}{|c|}{$\begin{array}{l}\text { Com o método PPSIG, fatores de qualidade } \\
\text { individualmente significativos podem ser facilmente } \\
\text { analisados em relação a outras camadas de informação. }\end{array}$} & \multicolumn{2}{|c|}{$\begin{array}{l}\text { As informaç̃oses coletadas com a PPSIG podem levar } \\
\text { a soluções diferentes das que teriam sido alcancadas } \\
\text { utilizando-se apenas fontes oficias de dados e o } \\
\text { conhecimento especialista. }\end{array}$} \\
\hline & $\mathbf{N}^{0}$ & $\%$ & $\mathbf{N}^{0}$ & $\%$ \\
\hline CT & 7 & 36,8 & 7 & 36,8 \\
\hline$C$ & 10 & 52,6 & 9 & 47,4 \\
\hline NCND & 2 & 10,5 & 2 & 10,5 \\
\hline$D$ & 0 & 0 & 0 & 0 \\
\hline DT & 0 & 0 & 1 & 5,3 \\
\hline Total & 19 & 100 & 19 & 100 \\
\hline
\end{tabular}

Fonte: Elaborado pelos autores.

Nota: AU = arquitetos e urbanistas; PPSIG = Participação Pública com Sistema de Informação Geográfica; $C \mathrm{~T}$ = concordo totalmente; $\mathrm{C}=$ concordo; NCND = nem concordo nem discordo; D = discordo; DT = discordo totalmente.

Tabela 5 - As informaç̃oes coletadas com a PPSIG podem dificultar ainda mais a tarefa do planejamento urbano, e as informaç̃ões coletadas são difíceis de interpretar

\begin{tabular}{|c|c|c|c|c|}
\hline & \multicolumn{2}{|c|}{$\begin{array}{l}\text { As informações coletadas com a PPSIG podem dificultar } \\
\text { ainda mais a tarefa do planejamento urbano, pois } \\
\text { acrescenta uma camada extra de informação. }\end{array}$} & \multicolumn{2}{|c|}{$\begin{array}{l}\text { As informações coletadas com a PPSIG são difíceis de } \\
\text { interpretar, pois são vagas. }\end{array}$} \\
\hline & $\mathbf{N}^{\circ}$ de $\mathrm{AU}$ & $\%$ & $N^{0}$ de $\mathrm{AU}$ & $\%$ \\
\hline CT & 0 & 0 & 0 & 0 \\
\hline$c$ & 2 & 10,5 & 3 & 15,8 \\
\hline NCND & 3 & 15,8 & 4 & 21,1 \\
\hline$D$ & 6 & 31,6 & 7 & 36,8 \\
\hline DT & 8 & 42,1 & 5 & 26,3 \\
\hline Total & 19 & 100 & 19 & 100 \\
\hline
\end{tabular}

Fonte: Elaborado pelos autores.

Nota: $\mathrm{AU}=$ arquitetos e urbanistas; PPSIG = Participação Pública com Sistema de Informação Geográfica; $\mathrm{CT}=$ concordo totalmente; $C=$ concordo; NCND = nem concordo nem discordo; D = discordo; DT = discordo totalmente. 
planejamento são criadas, distribuídas, processadas e usadas (Staffans et al., 2010).

Quanto à afirmação de que "As informações coletadas com a PPSIG podem dificultar ainda mais a tarefa do planejamento urbano, pois acrescenta uma camada extra de informação: a opinião do público", a maioria dos respondentes $(73,7 \%$, ou 14 de 19$)$ discorda $(31,6 \%$, ou 6 de 19$)$ ou discorda totalmente $(42,1 \%$, ou 8 de 19) (Tabela 5).

Nota-se, pelos comentários, que, embora os AU reconheçam que adicionar a opinião do público traz ainda mais complexidade à prática do planejamento urbano, tal informação é bem-vinda, pois o qualifica e tende a tornar os resultados mais efetivos. Para o entrevistado $\mathrm{N}$, é cada vez mais difícil lidar com tanta informação, mas é melhor ter um excesso de informação e poder fazer o filtro técnico. Segundo o entrevistado 0 , caso a opinião do público não seja considerada, posteriormente as soluções podem vir a ser questionadas, ou seja, perguntar antes significa antecipar-se aos problemas. Ainda, mesmo que a quantidade de informação que se tem antes, durante e inclusive ao longo da construção da cidade seja muito grande, o planejador tem que dar conta de todo esse montante, isto é, ter capacidade de filtrar o que interessa, abstrair o que não interessa e aplicar o que for possível. Nesse sentido, a utilização das informações coletadas com a PPSIG também se traduziria em ganhos de eficiência na gestão urbana por meio de uma maior aceitação social das propostas, em conformidade com Rantanen \& Kahila (2009).

Na mesma direção, a maioria dos AU discorda totalmente $(26,3 \%$, ou 5 de 19$)$ ou discorda $(36,8 \%$, ou 7 de 19) da afirmação de que "As informações coletadas com a PPSIG são difíceis de interpretar, pois são vagas" (Tabela 5). Diversos comentários dão conta de que tudo depende de como a ferramenta é elaborada, por exemplo:

Depende de como será a plataforma. Ela pode apontar questões pontuais para votação ou pode ser extremamente aberta para comentários (dessa forma, será necessário um agrupamento dos comentários por tema) (AU 46).

Ainda, destacam-se os seguintes comentários: "De fato são difíceis de interpretar, mas não porque 'são vagas', talvez sejam bem precisas, mas não conseguem incluir a riqueza das discussões presenciais nem a profundidade das análises espaciais avançadas" (AU 24); "Se a população não estiver capacitada e se o método utilizado não for muito objetivo, podem surgir informações muito vagas. O mesmo ocorre com informações coletadas através de métodos tradicionais (presenciais)" (AU 43); e "As informações contêm, além da resposta do usuário, a variável espacializada, que é fundamental no processo de planejamento urbano" (AU 26). Enquanto o primeiro relaciona a qualidade da opinião do público com os métodos presenciais, o segundo acredita que, se o público não estiver capacitado para participar, qualquer método pode ser falho. A primeira visão valida que a utilização de várias técnicas participativas é o ideal a ser buscado, já que a participação on-line não substitui a presencial, mas a complementa (Rojas \& Puig-i-Abril, 2009). A segunda ilustra que, embora sejam minoria, alguns profissionais ainda veem o público como tendo um déficit de conhecimento, conforme discutido por Corburn (2003). Por fim, a última manifestação valoriza um importante diferencial do método PPSIG, apontado por Poplin (2012): a conveniência de se ter os dados coletados de forma automatizada e georreferenciados, o que, diferentemente do que ocorre nos encontros presenciais, agrega uma valiosa informação à opinião do público - a sua localização -, facilitando consideravelmente a sua interpretação, análise e, consequentemente, incorporação no planejamento urbano.

Na sequência, há um questionamento, da parte dos respondentes, sobre a legibilidade e a utilidade do mapa para o planejamento urbano (Figura 1). Ele foi produzido a partir de dados coletados em um experimento PPSIG realizado em Jaguarão, no Estado do Rio Grande do Sul (Bugs, 2014). Ainda que parte dos respondentes tenha considerado a legibilidade do mapa satisfatória (47,4\%, ou 9 de 19), um número não desprezível a considerou nem satisfatória nem insatisfatória (21,1\%, ou 4 de 19) e mesmo insatisfatória (31,6\%, ou 6 de 19) (Tabela 6). Foram feitas algumas críticas, principalmente, referente ao gradiente utilizado para representar as faixas de renda e à classificação por cores dos pontos marcados pelos participantes (branco: sem classificação; coloridos: classificação segundo os comentários dos respondentes).

Assim, observa-se que, embora um exercício de sobreposição de informações, que objetiva mostrar relações entre varáveis e diferentes interpretações da questão em pauta, seja um instrumento fundamental de análise para o planejamento urbano, ele não é tão fácil de ser produzido, em sintonia com Kahila \& Kyttä (2009). No caso, foram sugeridas algumas alterações relativamente simples de se executar: atenção ao 


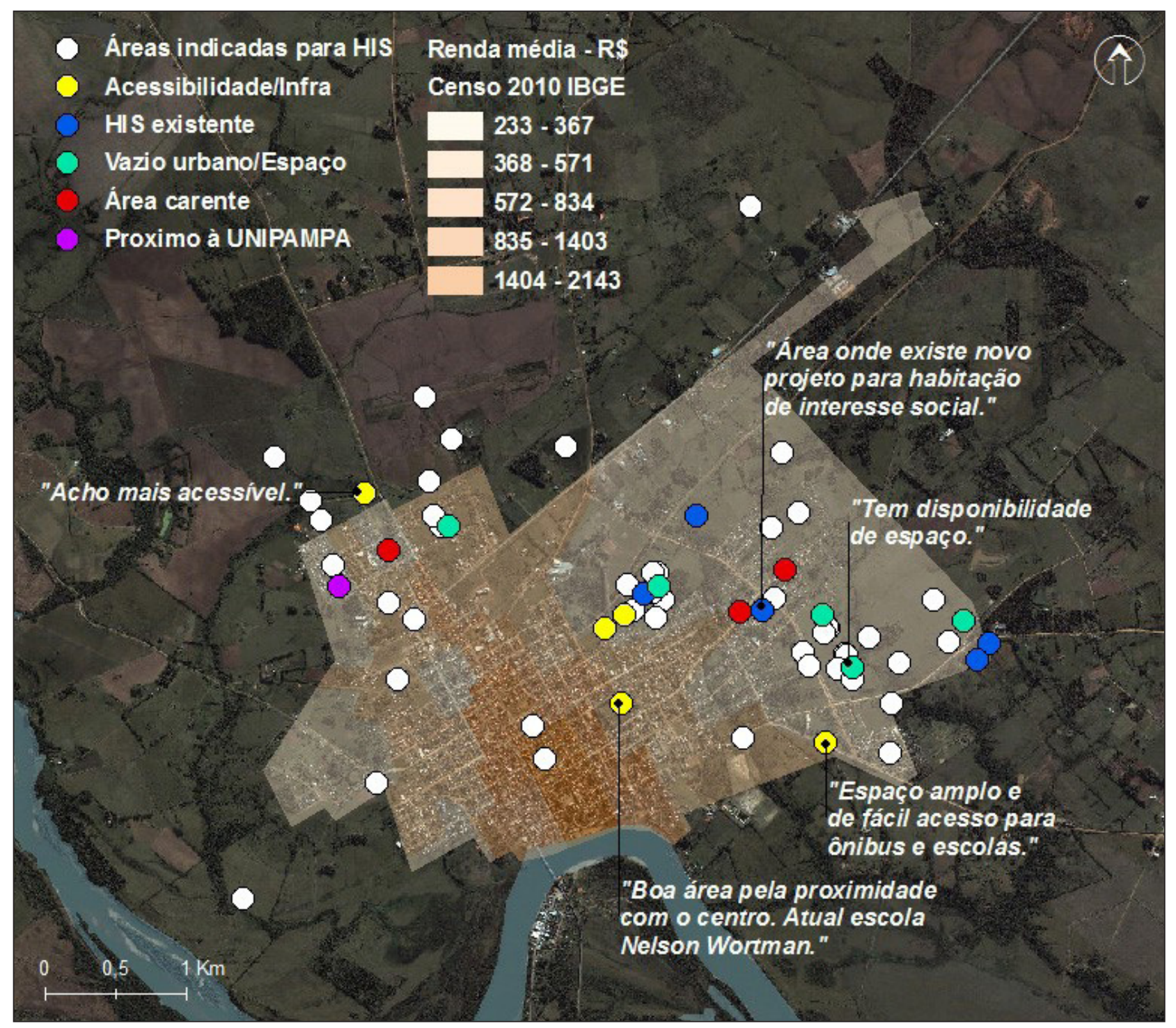

Figura 1 - Mapa apresentado no questionário

Fonte: Elaborado pelos autores.

Nota: HIS - Habitação de Interesse Social; UNIPAMPA - Universidade Federal do Pampa.

Tabela 6 - Como você avalia a legibilidade e a utilidade deste mapa

\begin{tabular}{|c|c|c|c|c|c|}
\hline \multicolumn{3}{|c|}{ Como você avalia a legibilidade deste mapa? } & \multicolumn{3}{|c|}{ Como você avalia a utilidade deste mapa? } \\
\hline & $\mathbf{N}^{\circ}$ & $\%$ & & $\mathbf{N}^{\circ}$ & $\%$ \\
\hline Plenamente satisfatória & 0 & 0 & Muito grande & 7 & 36,8 \\
\hline Satisfatória & 9 & 47,4 & Grande & 9 & 47,4 \\
\hline Nem satisfatória nem insatisfatória & 4 & 21,1 & Nem grande nem pequena & 2 & 10,5 \\
\hline Insatisfatória & 6 & 31,6 & Pequena & 1 & 5,3 \\
\hline Plenamente insatisfatória & 0 & 0 & Muito pequena & 0 & 0 \\
\hline Total de respondentes & 19 & 100 & Total de respondentes & 19 & 100 \\
\hline
\end{tabular}

Fonte: Elaborado pelos autores. 
gradiente de cores e/ou transparência na sobreposição com imagens; e informação correta da fonte dos dados. Não obstante, entende-se que ainda se tem um longo caminho no tocante à visualização e interpretação da informação geográfica (geovisualização) para o planejamento urbano.

Nas entrevistas, questionou-se como o dado coletado com a PPSIG pode ser utilizado no planejamento urbano, haja vista que essa é uma questão importante, mas, por vezes, negligenciada, pois não raramente se coletam dados que não são utilizados depois (Rantanen \& Kahila, 2009). Na opinião dos entrevistados, a questão passa, principalmente, pela correta incorporação da tecnologia SIG no planejamento urbano e pela capacitação técnica dos planejadores para utilizá-la.

$\mathrm{Na}$ opinião de um AU que trabalha no poder público, a análise dos dados coletados deveria ser feita por terceiros: "A informação tem que chegar estruturada, em um nível pronto para a apreensão do técnico, senão o técnico não vai parar e ficar olhando resultado por resultado, porque o cliente dele não é um, mas são milhares" (Entrevistado J). Essa visão se relaciona com o fato de que lidar com mais uma camada de informação, a qual, conforme destacado, não é simples de ser representada e analisada, e agrega dificuldades extras (por exemplo, disponibilidade de tempo) à complexa prática do planejamento urbano.

Sendo assim, observa-se que, apesar dos avanços ferramentais e tecnológicos, ainda há uma certa dificuldade para se realizar análises estatísticas e trabalhar com SIG, o que se configura na principal barreira à incorporação dos dados coletados com a ferramenta PPSIG no planejamento urbano. Similarmente, Göçmen \& Ventura (2010) afirmam que nos Estados Unidos, o potencial dos SIG como ferramenta de planejamento não está sendo totalmente explorado. A capacitação dos técnicos, especificamente em aplicações de SIG no planejamento urbano, é a principal medida que deve ser tomada para alterar essa realidade, segundo os autores.

Também questionou-se os entrevistados sobre "Como você vê as seguintes possibilidade de aplicação da PPSIG: (i) para coletar a percepção e/ou opiniões da população antes de um diagnóstico e/ou de uma etapa de desenvolvimento de projeto, e/ou (ii) como um sistema de monitoramento permanente?". No primeiro caso, a percepção da população sobre determinado tema seria coletada antes de uma etapa inicial de diagnóstico ou de projeto e, por conseguinte, incorporada na fase propositiva. 0 segundo caso seria a utilização constante da ferramenta para coletar a percepção da população.

Em geral, para os entrevistados, ambas possibilidades são positivas e desejáveis. Todavia, alguns destacaram que a primeira é mais difícil, porque consultar a população antes de realizar um projeto ou proposta ainda não é uma prática comum. Assim, para alguns, a aplicação como uma ferramenta de monitoramento é mais factível. Nas palavras do entrevistado J:

É o requinte da participação o governo perguntar antes de fazer alguma coisa o que se quer. Então, ter esta ferramenta para monitoramento do que está sendo feito e colocar isso para o conhecimento do público já é muito válido.

Já o entrevistado 0 destaca a importância da aplicação como uma ferramenta de monitoramento, pois não se dispõe de um instrumento de coleta de informações em longo prazo. Logo, na sua visão, a capacidade de armazenar informação de forma sistemática por um período maior é um potencial da PPSIG. No entanto, o entrevistado K levanta a questão de que uma ferramenta de coleta permanente da opinião da população pode tornar-se um repositório de queixas e reclamações, ao passo que para o entrevistado 0 : "Na cidade tem que ter alguém que vai pegar aquele monte de queixas e vai fazer alguma coisa propositiva".

Há de se considerar ainda o interesse do público em utilizar a ferramenta PSSIG em cada um desses momentos. Para o entrevistado 0 , as pessoas em geral, mobilizam-se para enfrentar um problema, e, por isso, uma aplicação pontual da ferramenta atrairia maior interesse do público, uma vez que "ninguém liga para dizer que boa está a sua administração; ligam para dizer que ali tem um buraco". Então, para ele, a aplicação da PPISG para enfrentar um problema específico seria o mais adequado.

Enfim, uma solução plausível foi apontada pelo entrevistado D, no sentido de utilizar a PPSIG como um canal permanente de coleta da percepção da população, mas que mudaria o tema em questão ao longo do tempo:

Acho que o fundamental é manter a ferramenta de mapeamento pela internet mais ou menos permanente. Por exemplo, nós vamos fazer o plano diretor, esta ferramenta está; se nós vamos fazer uma melhoria na praça, esta ferramenta está [...]. Como sempre há alguma coisa, esta ferramenta estaria aplicada a cada momento. 
Portanto, conclui-se que aplicar a PPSIG de forma contínua no planejamento urbano, porém sempre voltada a questões objetivas e pontuais, ou seja, a projetos urbanos específicos, e não a problemas abrangentes, parece ser mais apropriado, pois, desse modo:

- O público se mobilizaria mais;

- As reclamações particularizadas seriam menos prováveis;

- 0 projeto proposto seria mais facilmente aceito;

- Seria possível comparar a opinião do público ao longo do tempo;

- O planejador teria o conhecimento local sempre à sua disposição.

\section{Conclusões}

Os resultados deste estudo indicam que, apesar da complexidade de se lidar com a opinião do público, o conhecimento local é considerado fundamental e, portanto, caracteriza-se como uma camada de informação indispensável para tornar o planejamento urbano mais efetivo. Contudo, por muito tempo o conhecimento especialista reinou de forma absoluta no planejamento urbano. Para diminuir a divisão entre expertos e leigos, e difundir a noção de que melhores soluções e ideias surgem a partir do envolvimento de pessoas leigas e seu conhecimento tácito do que aquelas desenvolvidas apenas por especialistas (Pfeffer et al., 2013), assumese, em conformidade com o planejamento agonístico (Mäntysalo et al., 2011), que a racionalidade surge da interação entre uma série de atores, cada um defendendo os seus objetivos e interesses.

A não aceitação e, por conseguinte, a não aplicação da opinião do público nas propostas são apontadas como sendo um dos motivos pelos quais o planejamento urbano não responde às demandas dos cidadãos e aos desafios da complexa realidade urbana. Nesse sentido, a efetiva incorporação do conhecimento local no planejamento passa, principalmente, por questões estruturais e ideológicas. Para que o conhecimento local seja incorporado adequadamente no planejamento urbano, as estruturas de poder existentes devem aceitar que segmentos leigos da sociedade têm valiosos conhecimentos e podem contribuir substancialmente para as decisões de planejamento e de gestão urbana.
Em geral, há um medo de se perder o controle do processo e é difícil para o técnico compartilhar a definição das soluções com aqueles que não investiram tempo e esforço para obter formação técnica, conforme aponta Brown (2012).

Contudo, percebe-se a existência de um entendimento o qual demonstra que essa postura prejudica o sucesso da atividade. Também, que está em curso um processo de mudança no modo de se fazer planejamento urbano, reforçada pela noção de o planejador urbano ter o dever de ser um mediador dos diferentes interesses envolvidos no planejamento urbano, isto é, aquele que busca a concertação entre as partes por meio da utilização dos seus conhecimentos técnicos, em conjunto com o conhecimento dos demais (Souza \& Rodrigues, 2004; Staffans et al., 2010). A experiência profissional dos planejadores não deixa de ser valorizada e suas competências são reforçadas com a inclusão das informações e ideias produzidas por vários atores. Assim, o saber do técnico/especialista não substitui a experiência dos cidadãos, mas tal experiência é incluída de forma colaborativa no planejamento (Innes \& Booher, 2004).

No entanto, a despeito de que os avanços tecnológicos estão produzindo um novo contexto em que um grupo maior de cidadãos está se habilitando a participar no planejamento urbano, evidenciou-se, neste estudo, que ainda não há consenso entre os profissionais sobre como considerar os dados produzidos pelos cidadãos nas suas atividades cotidianas, como os oriundos do uso de smartphones ou de atividades voluntarias e/ou colaborativas de mapeamento. Assim, o aproveitamento das informações produzidas pelos cidadãos de forma "espontânea" por meio das tecnologias digitais ainda é uma questão em debate, conforme salientado por Pereira et al. (2013).

No entanto, mesmo considerando as limitações da amostra deste estudo, pode-se dizer que os $\mathrm{AU}$ que trabalham com planejamento urbano tendem a desejar utilizar novas tecnologias no planejamento urbano e estão abertos à participação do público. Nesse sentido, a ampliação da participação pública e a utilização de novas ferramentas passam pela adoção de novas metodologias de trabalho, bem como maior capacitação técnica para se lidar tanto com a opinião do público quanto com os novos fluxos de informação da era digital.

Com relação à avaliação do método PPSIG, os resultados indicam que é consenso entre os especialistas 
participantes da amostra que tal método possibilita acessar e incorporar o conhecimento local no planejamento urbano de forma sistemática e que esse conhecimento, por ser uma fonte única de informações atualizadas, ajuda a melhorar a qualidade do conteúdo dos planos e/ou projetos urbanos. Além disso, os AU concordam que a percepção da população deveria formar uma camada adicional de informações e ser analisada em conjunto com as demais camadas necessárias ao planejamento urbano.

Porém, para que isso ocorra, há a necessidade de se ampliar o conhecimento técnico para que os dados coletados com a PPSIG possam ser analisados e, por conseguinte, incorporados no planejamento urbano de forma consistente. Assim, a relativa falta de conhecimento sobre os SIG configura-se em barreira à incorporação dos dados coletados com a PPSIG no planejamento urbano, o que indica a necessidade de capacitação técnica.

Também foi citado que a utilização de metodologias como a PPSIG se traduziria em ganhos de eficiência por meio de uma maior aceitação social das propostas. A PPSIG facilita que a opinião do público seja considerada na construção das propostas, uma vez que contém a variável espacializada. Mas, para que a interpretação das informações coletadas com a PPSIG seja satisfatória, a elaboração da ferramenta e das perguntas que preveem a marcação de lugares no mapa on-line interativo deve ser definida conforme os objetivos da pesquisa a fim de se coletar somente informações claras e úteis para o planejamento.

Logo, mesmo que ainda existam barreiras para se trabalhar em um plano mais elevado de colaboração com a população, demonstrou-se, conforme as opiniões dos especialistas consultados neste estudo, que novas metodologias participativas, que tirem partido das TIC e dos SIG, tal como a PPSIG, podem auxiliar significativamente na difícil tarefa de acessar e incorporar o conhecimento local no planejamento urbano. 0 uso permanente da ferramenta PPSIG para coletar a percepção da população, sempre que aplicado a questões objetivas e pontuais, é apontado pelos AU como sendo desejável e positivo.

Ainda, conforme a avaliação dos especialistas, conclui-se que o planejamento urbano participativo por meio da utilização de novas tecnologias, tal como a PPSIG, poderia permear todo o processo de planejamento, desde a coleta de informações sobre a percepção da população acerca de determinado tema, antes mesmo da elaboração das propostas, até o monitoramento da opinião da população ao longo do processo.

Concluindo, espera-se que os resultados desta pesquisa auxiliem a reforçar a necessidade de uma postura, por parte daqueles envolvidos com o planejamento urbano, que esteja aberta à inclusão do conhecimento local por meio da utilização de novas tecnologias, tais como a PPSIG, necessidade esta já identificada em outros estudos (Batty et al., 2012; Pereira et al., 2013).

\section{Referências}

Batty, M., Axhausen, K. W., Giannotti, F., Pozdnoukhov, A., Bazzani, A., Wachowicz, M., Ouzounis, G., \& Portugali, Y. (2012). Smart cities of the future. The European Physical Journal. Special Topics, 214(1), 481-518. http://dx.doi. org/10.1140/epjst/e2012-01703-3.

Brown, G. (2012). Public Participation GIS (PPGIS) for regional and environmental planning: reflections on a decade of empirical research. URISA Journal, 24(2), 7-18.

Bugs, G. (2014). Tecnologias da informação e comunicação, sistemas de informação geográfica e a participação pública no planejamento urbano (Tese de doutorado). Programa de Pós-graduação em Planejamento Urbano e Regional, Universidade Federal do Rio Grande do Sul, Porto Alegre.

Carver, S. (2001). Participation and Geographical Information: a position paper. In Proceedings of the ESF-NSF Workshop on Access to Geographic Information and Participatory Approaches Using Geographic Information (p. 1-19). Spoleto: National Science Foundation.

Conselho de Arquitetura e Urbanismo - CAU. (2014). Censo dos Arquitetos e Urbanistas do Brasil. Recuperado em 21 de maio de 2014, de www.caubr.gov.br/censo

Corburn, J. (2003). Bringing local knowledge into environmental decision making improving urban planning for communities at risk. Journal of Planning Education and Research, 22(4), 420-433. http://dx.doi.org/10.1177/07 39456X03022004008.

Forester, J. (2006). Making participation work when interests conflict: moving from facilitating dialogue and moderating debate to mediating negotiations. Journal of the American Planning Association, 72(4), 447-456. http:// dx.doi.org/10.1080/01944360608976765. 
Friedmann, J. (2007). A spatial framework for urban policy: new directions, new challenges. In Proceedings of the OECD International Conference: "What Policies for Globalising Cities? Rethinking the Urban Policy Agenda" ( $\mathrm{p}$. 74-88). Madrid: OECD.

Göçmen, Z. A., \& Ventura, S. J. (2010). Barriers to GIS use in planning. Journal of the American Planning Association, 76(2), 172-183. http://dx.doi.org/10.1080/01944360903585060.

Hall, G. B., Chipeniuk, R., Feick, R. D., Leahy, M. G., \& Deparday, V. (2010). Community-based production of geographic information using open source software and Web 2.0. International Journal of Geographical Information Science, 24(5), 761-781. http://dx.doi.org/10.1080/13658810903213288.

Haller, C., \& Höffken, S. (2010). New Communication Tools and eParticipation: Social Media in Urban Planning. In M. Schrenk, V. Popovich, \& P. Zeile. Proceedings of the $X V$ International Conference on Urban Planning, Regional Development and Information Society. RealCORP 2010 (pp. 18-20). Vienna: CORP.

Horelli, L. (2002). A methodology of participatory planning. In R. B. Bechtel, \& A. Churchman (Eds.). Handbook of environmental psychology (pp. 607-628). Nova Iorque: John Wiley \& Sons.

Horelli, L., Jarenko, K., Kuoppa, J., Saad-Sulonen, J., \& Wallin, S. (2013). New approaches to urban planning-insights from participatory communities. Espoo: Aalto University.

Hudson-Smith, A., \& Crooks, A. (2008). The renaissance of geographic information: neogeography, gaming and second life (Vol. 142, Working Papers Series, p. 1-16). London: University College London.

Innes, J. E., \& Booher, D. E. (2004). Reframing public participation: strategies for the 21st century. Planning Theory \& Practice, 5(4), 419-436. http://dx.doi.org/10.1 080/1464935042000293170.

Kahila, M., \& Kyttä, M. (2009). SoftGIS as a bridge-builder in collaborative urban planning. In S. Geertman, \& J. Stillwell (Eds.), Planning support systems best practice and new methods (p. 389-411). Netherlands: Springer.

Mäntysalo, R., Balducci, A., \& Kangasoja, J. (2011). Planning as agonistic communication in a trading zone: Re-examining Lindblom's partisan mutual adjustment. Planning Theory, 10(3), 257-272. http://dx.doi.org/10.1177/1473095210397147.

Pereira, G. C., Florentino, P. V., \& Rocha, M. C. F. (2013). City as a social network - Brazilian examples. In C. Ellul,
S. Zlatanova, M. Rumor \& R. Laurini (Eds.), Urban and Regional Data Management: UDMS Annual 2013 (p. 129). Boca Raton: CRC Press.

Pfeffer, K., Baud, I., Denis, E., Scott, D., \& Sydenstricker-Neto, J. (2013). Participatory spatial knowledge management tools: empowerment and upscaling or exclusion? Information Communication and Society, 16(2), 258-285. http://dx.doi. org/10.1080/1369118X.2012.687393.

Poplin, A. (2012). Web-Based PPGIS for Wilhelmsburg, Germany: An Integration of Interactive GIS-based Maps with an Online Questionnaire. URISA Journal, 24(2), 75.

Rantanen, H., \& Kahila, M. (2009). The SoftGIS approach to local knowledge. Journal of Environmental Management, 90(6), 1981-1990. http://dx.doi.org/10.1016/j. jenvman.2007.08.025. PMid:18556113.

Rojas, H., \& Puig-i-Abril, E. (2009). Mobilizers mobilized: Information, expression, mobilization and participation in the digital age. Journal of Computer-Mediated Communication, 14(4), 902-927.http://dx.doi.org/10.1111/j.1083-6101.2009.01475.x.

Sieber, R. (2006). Public participation geographic information systems: a literature review and framework. Annals of the Association of American Geographers, 96(3), 491-507. http://dx.doi.org/10.1111/j.1467-8306.2006.00702.x.

Souza, M. L., \& Rodrigues, G. (2004). Planejamento urbano e ativismo sociais. São Paulo: UNESP.

Staffans, A., Rantanen, H., \& Nummi, P. (2010). Online environments shake up urban planning-developing local internet forums. In S. Wallin, L. Horelli, \& J. Saad-Sullonen (Eds.), Digital tools in participatory planning (p. 37-58). Espoo: Aalto University.

Villaça, F. (2005). As ilusões do Plano Diretor. São Paulo. Recuperado em 3 de setembro de 2015, de http://www. flaviovillaca.arq.br/livros01.html

Wallin, S., \& Horelli, L. (2012). Playing with the glocal through participatory e-planning. The Journal of Community Informatics, 8(3). Recuperado em 3 de setembro de 2015, de http://ci-journal.net/index.php/ciej/article/view/883/934

Yigitcanlar, T. (2006). Australian local governments' practice and prospects with online planning. URISA Journal, 18(2), 7-17.

Recebido: Set. 03, 2015

Aprovado: Jan. 12, 2016 